\title{
Innovative process of education: non-finite verbal paradigm development as a proof of the English language pidginization
}

\author{
Alina Sokolova, ${ }^{1, *}$ and Julia Fedurko ${ }^{2}$ \\ ${ }^{1}$ Tver State Medical University, Latin and Foreign Languages Department, 1701004 ul. Sovetskaya \\ Tver, Russia \\ ${ }^{2}$ Dmitrov Institute of Continuing Education, Department of Humanities and Social Sciences, 141802, \\ 33 ul. Kosmonavtov, Dmitrov, Russia
}

\begin{abstract}
This article deals with the question of whether English was subject to pidginization or not. Different points of view are presented but to answer the question definitely is not possible since there are no specific criteria to define a language as a contact one. However, the necessary external conditions for pidginization actually existed in the history of the English language, and a mechanism similar to the mechanism of the creolization process took place. This conclusion can be proved by the analysis of different elements of the English grammar. This article presents the results of the comparative diachronic research of non-finite verbal paradigm in the English language.
\end{abstract}

\section{Introduction}

The purpose of this study is defined by the fact that many elements of the grammatical system of modern English are significantly different from their counterparts of the Old English period. The reasons for this discrepancy are not clear. The aim of this article is to look closely at the most probable version that is the break of the literary tradition, caused by the prevailing extra linguistic circumstances leading to extensive language contacts of the English language with other languages.

\section{Materials and methods}

This article is a generalization of the results of a more in-depth study, during which the socio-historical conditions for the implementation of language contacts of the English language in the Middle Ages were studied; languages that could have a significant impact on the development of the English language were identified. A large corpus of Old English, Middle English and Early English texts was analyzed; the elements constituting non-finite verbal paradigm were studied extensively from the point of view of their form, functions and semantics.

* Corresponding author: alinasokolova.tver@yandex.ru 
The material of the study was the texts in which the trends of language development in a certain historical period are most clearly reflected. In this paper, the traditional periodization of the history of the English language is adopted: the Old English period until the end of the 11th century; Middle English - from the end of the XI to the end of the XV century; New English - from the end of the XV century up to the present.

In order to analyze the material and solve the set tasks we applied a method of historical research, the use of which allowed analyzing the dynamics of the development of non-finite forms as a linguistic phenomenon throughout the history of the language and made it possible to note the peculiarities of non-finite forms in various functional and stylistic varieties of texts; the whole set of language research methods, including comparative analysis (comparison of non-finite and finite forms, comparison of their functions in different historical periods, in different languages); contextual analysis of semantics; categorization, lexico-semantic fields, system approach, and others. The complexity of the language material chosen as the object of study leads to a comprehensive functional approach to its consideration.

\section{Theory}

The question of pidginization and creolization of English was sufficiently developed in the writings of Charles Bailey and Karl Maroldt. They considered Middle English as a completely new system, unlike the Old English language, which was formed as a result of mixing two or more languages: "gradient mixture of two or more languages ... [the] result of mixing which is substantial enough to result in a new system ... separate from its antecedent parent systems" [1].

The starting point of this problem is considered the question of the existence of the English pidgin. Manfred Görlach gave two proofs of the presence of the English pidgin simplification and confusion of languages, which, in his opinion, is considered not sufficient: "The existence of an English pidgin on British soil has never been postulated ... unless simplification and language mixture are thought to be sufficient criteria for the definition of a creole or creoloid..., then Middle English does not appear to be a creole" [2]. However, as it was noted by Patrissia Poissa [3], the initial point of creolization can be not only pidgin, but also a pre-pidginization continuum or some other minor type of language: "pre-pidgin continuum or subordinated language-variety of some other sort".

Proponents of the theory of the creolization of the English language identify the following criteria for creolization. For example, James Milroy gives the following signs: "(1) gross morphological simplification; (2) some loss of segmental phonological distinctions; (3) relexification; (4) a preference for a fixed SVO word-order" [4]. J. Milroy gives evidence that at least three of the four signs (1,3, and 4) are present in Middle English. P. Poissa, comparing Old English with the early New English language, notes the existence of such characteristics of the process of creolization as «a) loss of grammatical gender; b) extreme simplification of inflexions; c) borrowing of common lexical words and some form-words» [3]. And it is precisely by these traits, as the author continues, that the development of the English language differs from the development of the related languages of the West and North Germanic subgroups.

Andrei Danchev tries to summarize all creolization signs, bringing them into a single table (see Tab. 1), adding comparisons with other Creole languages [5].

Source: Data adopted from Danchev, A. 1997. The middle English Creolization Hypothesis revisited. Studies in Middle English. Berlin, New York: Mouton de Gruyter: 96.

The presence or, on the contrary, the absence of many of the features shown in the table in Middle English is quite controversial. Thus, Middle English with emerging analytical constructions can hardly be described as having no pre-verbal markers of time, mood, or 
aspect. One way or another, according to this table, Middle English has a 50\% similarity with other Creole languages.

Table 1. Creolization signs in Middle English in comparison to other Creole languages.

\begin{tabular}{|l|c|c|}
\hline & Middle English & Creole Languages \\
\hline Simplified segmental phonology & + & + \\
\hline Prevailingly open syllable structure & - & + \\
\hline Lack of (reduced) noun morphology & + & + \\
\hline No (reduced) gender marking & + & + \\
\hline SVO order & + & - \\
\hline Morpho-syntactically marked passive & + & + \\
\hline Preverbal tense, mood and aspect marking & - & + \\
\hline Verbal serialization & + & + \\
\hline Verbal periphrases & - & + \\
\hline Reduced use of be-copulas & - & - \\
\hline Use of the same verb for possession and existence & + & + \\
\hline Non-finite verbal forms & + & + \\
\hline Relexification & - & + \\
\hline Lexical circumlocution & + & + \\
\hline Overall analyticity & & + \\
\hline
\end{tabular}

Calling English in different ways: creole, creoloid, mixed language, hybrid, scientists agree on one thing: a mechanism similar to the mechanism of the creolization process took place in the development of English.

The main disagreement in the theory of the creolization of the English language is the lack of a precisely defined language, under the influence of which English has changed so much. Charles Bailey and Karl Maroldt consider French to be such a language. They distinguish two periods of the influence of the French language on English: the main influence of the old French language until 1200 and the minor influence of the French language in the 13th and 14th centuries. Their conclusions are based on the results of the study primarily on the percentage of lexical borrowings from the French language, compound words, which are a combination of French and Anglo-Saxon roots and affixes, as well as particular points of phonetics, grammar and syntax.

Anthony Warner, supporting the theory of creolization, highlights the influence of Latin, and Patricia Poissa - of Scandinavian languages [6; 3].

Otto Jesperson, without using sociolinguistic terms pidginization and creolization, identifies three significant factors (waves of influence) in the history of the English language - Scandinavian, French and Latin: "three very important factors in the development of the language, three superstructures, as it were, that came to be erected on the Anglo-Saxon foundation, each of them modifying the character of the language, and each preparing the ground for its successor. A Scandinavian element, a French element, and a Latin element now enter largely into the texture of the English language" [7]. O. Jespersen pays attention, first of all, to lexical borrowings, without denying, however, the influence on the grammatical structure. The author does not provide any evidence. So, when considering the issues of Scandinavian influence, he notes only the disappearance and alignment of some grammatical forms as a result of language contact: "As the Danes and the English could understand one another without much difficulty it was natural that many nice ties of grammar should be sacrificed, the intelligibility of either tongue coming to depend mainly on its mere vocabulary. So when we find that the wearing away and levelling of grammatical forms in the regions in which the Danes chiefly settled was a couple of centuries in advance of the same process in the more southern parts of the country, the conclusion does not seem unwarrantable that this is due to the settlers who did not care to learn English correctly in every minute particular and who certainly needed no such accuracy in order to make themselves understood". Speaking about the significant influence of the Latin language on English grammar, Otto Jespersen gives just one example 
- the absolute participial construction, which became quite common at the end of the Middle English period [7].

Otto Jespersen underlines the destruction of the grammatical system, he tells about breaking the tradition. Comparing the case system of Old English and modern English, he wonders why it has changed so much. He quotes Grimm, who mentions the destruction of the grammatical structure of a language as a result of language contacts: "Any violent mixture of two languages is against nature, and results in a rapid destruction of the forms of both. When a great mass of French words rushed in upon the English language, few if any forms passed over to its grammar, but the Saxon forms suddenly collapsed, because they did not agree with the new roots, and because the genius of the language was led by the crude employment of the foreign material to neglect the native flexion. . . . This rapid sinking from the more perfect Anglo-Saxon forms ... is easily explained by influence from Danish and Norman-French. According to a universal and natural law, where two different tongues come in collision, grammatical forms are lost" [8]. Otto Jespersen denies the direct impact of the Norman conquest on the grammatical system of the English language. He considers this influence indirect. However, it as a result of the interruption of literary tradition leads to the destruction of the language structure.

Thus, there are several points of view on the theory of the creolization of the English language, the degree of influence of different languages on the development of the English language. In our study, we proceed from the fact that there is clear evidence that the grammatical structure of Middle English is significantly different from the Anglo-Saxon one. This is exactly the reason for the emergence of the theory of creolization, with which the authors try to explain such a significant change in the grammatical structure of the language.

The main argument of the opponents of the creolization theory of English is the fact that pidgin is usually considered to be a simplified version of the languages in contact or as W. Rothwell states "creolization assumes one of the languages is highly developed and the other more primitive". But none of Old English, Middle English, Central French nor AngloFrench, any of the Scandinavian languages can reasonably be considered highly developed or undeveloped [9].

The theory of Givon (the theory of the pragmatic code) offers a fairly conclusive explanation of the process that most likely took place in the history of the English language. This approach, as it seems, really suits the case of the English language. According to this theory, pidgin is not a product of simplification of a given language, but a product of a complete restructuring of this language: it passed the "pragmatic code" stage, after which it develops along a completely different model, in many cases unrelated to the models of the original language or languages with which it comes in contact. The concept of a "pragmatic code" put forward by T. Givon implies a set of strategies: a) the movement of the word order from theme to rheme; $b$ ) free coordination (absence of subordinate constructions); c) the ratio of nominal bases with the verb is minimal, approximately 1: 1; d) lack of inflectional morphology; e) special intonation - lowering the tone towards the theme, then moving to a melodic boost on the rheme; f) minimal anaforics and, accordingly, the starting phase of the development of pronouns as a grammatical category. Such features are formed in a situation of "communicative stress" - when it is necessary to solve problems jointly in the absence of a common language, on the background of minimal common pragmatic prerequisites for communication (since communicators belong to different cultural, social and other groups). These difficulties are partially resolved by the fact that communication takes place "here and now": the topic of conversation, the tasks of communication and the situation are obvious, perceived by the participants directly [10].

This state of the language is a starting point of the evolutionary cycle. At the level of a pragmatic code, the structures of different languages appear to be uniform. This stage takes 
place in the formation of contact languages. At this stage, as E.V. Perekhvalskaya explains, a "fundamental change of grammar" [11] happens and in a short period of time, the language turns out to be reduced to a situation close to a "pragmatic code" - a language without grammar. This happens not because the model of such a code is transferred from one speaker to another, and then implemented on a new language material, but because the pragmatic code itself turns out to be universal, that is, a property of the language in general. The language practically loses the existing grammatical system. And then a completely "new" grammar is built. T. Givon calls this process syntacticization — the deployment of a pragmatic code according to the grammar rules of a particular language. This theory is confirmed by the statement of M.V. Dyachkov, who underlines the uniformity of the mechanism of the formation of contact languages, but the difference in the results of this process [12].

A theory similar to the idea of a pragmatic code is put forward by Christine DaltonPuffer. Exploring the derivational morphology of the Middle English language, she concludes that the process of the language development of the English language has stopped or, as she calls it, came to language death or language shift, which is more appropriate in our opinion [13]. Considering Middle English as a remnant of the AngloSaxon, she identifies several indicators of the phenomenon of the "death of the language", confirming them with examples:

1). Absence of Anglo-Saxon proper names in the Middle English language: cessation of giving and using proper names in the recessive language is an early indicator of language death.

2). Changing the attitude of the speakers to their language.

3). Mitigation or loss of the grammatical rules: the speakers of the recessive language begin to consider their language as worthless which results in the relaxation of sociolinguistic and linguistic norms.

4). The use of Middle English is limited to informal, private communication: the recessive language becomes inadequate for certain speech situations, domains and functions.

5). The presence of lexical borrowings: situations of language death or language shift are characterized by massive lexical loans from the dominant to the recessive language while loans in the other directions occur only sporadically.

6). Unproductiveness of former word-formation models. The author gives an example of a drop in the productivity of the suffixes -ness and -the.

In conclusion, Christine Dalton-Puffer contrasts the notion of language death with the notion of language birth, which she equates to the process of creolization of the language. Both of these processes are different results of language contacts language birth (creoles) and language death - specific subsets of all the possible products of language contacts. As Middle English is undoubtedly a product of language contact, it is only natural that it should share certain features with creoles and also with recessive languages.

The above mentioned conclusions can be proved by the analysis of different elements of English grammar. This article presents the results of the comparative diachronic research of non-finite verbal paradigm in the English language.

Non-finite forms of the English verb are chosen for the research not by accident. They are one of the most mobile parts of the language system. Mobility is a sign of a changing language usage and, therefore, is an essential characteristic that allows you to identify significant points, the analysis of which gives an idea of the trends in the development of language levels and the language as a whole. The choice of non-finite forms is due to their wide and varied use in the literary texts of different historical periods. Non-finite forms capture several levels of the language hierarchy, simultaneously combining the features of several parts of speech. In the history of language, the part-of-speech characteristics of non- 
finite forms are transformed, and, as it is well known, the processes associated with the development of such universal categories as predicate, attribute, substantive, have typological significance. In addition, one of the most important moments of language development is the deployment of tense system, expressed in the formation of new, for the most part, analytical grammatical forms of the verb, in which non-finite forms are widely used.

\section{Results and Discussion}

As the analysis showed, the functions of non-finite forms undergo significant changes. All components of the non-finite paradigm of the Middle English verb differ greatly (formally, functionally and semantically) from the non-finite forms used in the Old English texts. At the same time, the recorded changes are not a continuation of the tendencies that emerged in the Old English period. The changes in non-finite verbal paradigm proves the fact that the grammatical structure of the Anglo-Saxon language reduces to the level of a pragmatic code as a result of various sociocultural circumstances and then begins further development under the new laws. These new trends include the gradual disintegration of inflectional and synthetic paradigms and the establishment of analyticity, root isolation and agglutination features.

The main directions of development of non-finite forms in the Middle English period include:

1. functional discrepancy of two forms of the infinitive

2. functional, and sometimes formal, convergence of non-finite forms of the verb with the finite ones

3. the prevalence of absolute (independent) use of non-finite forms

4. lack of endings and, therefore, absence of agreement with the word to be defined

5. mixing of non-finite forms: formal and functional.

In the early New English period, non-finite forms continue their development. The most significant trends are the following:

1. participation of all non-finite forms in analytical constructions

2. fixing of the syntactic position of non-finite forms in a sentence

3. the narrowing of the functions and valencies of the bare infinitive and participle II; expansion of the functions of to-infinitive and participle I, therefore, the expansion of their syntactic valencies.

Some non-finite forms (to-infinitive, participle I and, in most cases, participle II) are formed by adding affixes with clear boundaries to the root, which undoubtedly indicates a tendency to agglutination. The very form of bare infinitive is basic, formally similar to imperative, some forms of indicative and subjunctive mood. Other non-finite forms (except for Participle II) are formed with the help of affixes from the form of a bare infinitive. Affixes of non-finite forms join to any root, irrespective of their part-of-speech affiliation. At the same time, the affixes themselves are characterized by grammatical unambiguity they express only one grammatical meaning, that is, the belonging of the corresponding derived form to only one grammatical category. Grammatical categories of non-finite forms are not numerous (category of voice, duration and completion) and are of a relative nature, manifesting themselves only in relation to finite forms of the verb. The disappearance of inflectional affixes leads to the disappearance of formal coordination and government. Instead, syntactic links such as adjunction, logical agreement and analytical (prepositional) government are used.

The position of the non-finite forms in the sentence becomes fixed. The functional significance of the order of words in a sentence leads to the appearance of assemantization out of context. 
Non-finite forms practically do not demonstrate any correlation to certain parts of speech. Their syntactic valencies are expanded and the clear boundaries between non-finite forms are blurred. The same functions can be performed by different non-finite forms (toinfinitive and participle I, for example), which indicates their syntactic equivalence.

Most non-finite forms (participles and bare infinitives) are involved in analytical constructions.

Subpredication is widespread (the presence of secondary predicative structures, that is, such phrases whose components are interconnected by a predicative syntactic link). Often non-finite forms function in the framework of participial and infinitive constructions, performing an appositive function, in which the non-finite form represents different "ideas" with a defined word (noun or verb), and their functioning can be equated to a subordinate clause. Subpredication leads to the elimination of redundancy. Often a non-finite construction or the form itself allows you to convey the meaning of the whole sentence.

The above changes marked the beginning of a new structural principle for the organization of the paradigm of the verb in its non-finite part. In the Old English period, it could be represented by the following scheme (see Fig. 1):

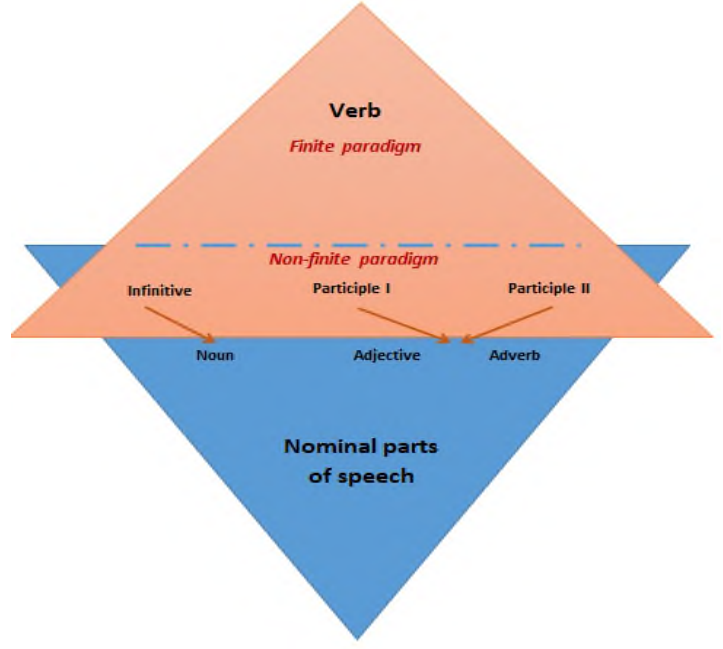

Fig. 1. Old English Verbal Paradigm.

The non-finite paradigm of the verb was a border region between the finite paradigm of the verb and nominal parts of speech. All three non-finite forms were focused on specific nominal parts of speech.

In the Middle English period, the process of transformations began in the non-finite paradigm. As a result, it has undergone significant changes (see Fig. 2).

Two non-finite forms - to-infinitive and participle I (-ing form) received universal functionality and valency, losing orientation to certain parts of speech. The bare infinitive has narrowed its use, has lost its substantive signs, thus practically (except for cases of very limited use in the "complex object" constructions) has turned into a finite form participating only in the analytical constructions with modal verbs opposed to all finite forms of the verb within the category of modality (potential mood).

A similar narrowing of the functions was also noted in Participle II. However, this was recorded in the Middle English period, when Participle II, unlike Participle I and toinfinitive, did not strengthen and expand its nominal functions, but reduced them to a minimum, being used mainly only in the framework of developing analytical forms. But in contrast to to-infinitive, which is increasingly narrowing its functions, Participle II gradually acquires attribute-adverbial functions and valency. 


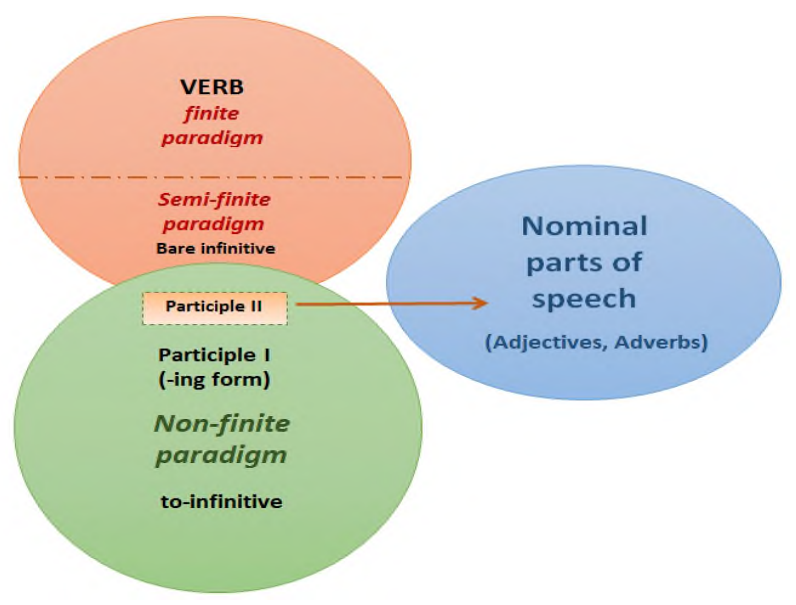

Fig. 2. Modern English Verbal Paradigm.

The verb paradigm has the following structural principles of organization. At the grammatical periphery of the verb, several steps of proximity to the core of the verbal paradigm - the finite verb - are distinguished. The nearest periphery is a semi-finite paradigm, which includes a bare infinitive. The use of bare infinitive in the "complex object" construction does not allow it to be completely excluded from the category of nonfinite forms. However, there are points of view that, in this construction, bare infinitive participates in the category of modality as well. In addition to the usage with modal verbs in modern English, bare infinitive is used in the "complex object" construction exclusively after the verbs of perception. Some researchers confirm that perception verbs are related to the category of modality. Verbs of perception in English are divided into subject-oriented and object-oriented. Subject-oriented verbs describe the action of perception on the part of the perceiver, who performs active actions to percept: Karen listened to music. Karen smelled the iris with delight [14]. Object-oriented perception verbs feature the perceived object as the sentential subject and the perceiver is sometimes wholly absent from the clause. Using object-oriented verbs of perception, the speaker evaluates the object of perception. Consequently, as some researchers note, these verbs have the meaning of "evidence" $[15 ; 14 ; 16]$ as perception verbs express different evidential meanings in English: direct sensory evidentiality or quotative evidentiality. Evidence, in the opinion of these and other researchers, is a type of modality.

The second stage of the verbal paradigm is the non-finite forms of participles, which also participate in analytical constructions. Participle I, like the form of to-infinitive, located at the most distant stage from the core of the verb paradigm, functionally approximates to other parts of speech, but show no signs of convergence with specific ones.

Participle II, apparently, is still at an intermediate stage of evolution. On the one hand, it is wider than all other non-finite forms used in the analytical constructions (in the Middle English period, almost exclusively in this function). On the other hand, in the New England period, the participle functions expand, and you can even see the substantive use of the participle, which indicates its possible functional universality.

Participle II remains on the border between the semi-final paradigm and the non-final paradigm of the verb, which is oriented to such nominal parts of speech as the adjective and adverb. It can be assumed that in this duality lies the potential for the further development of the participle, which can be channeled in two directions. On the one hand, Participle II loses its focus on certain parts of speech, acquiring semantically syntactic universality. On the other hand, Participle II, like bare infinitive, narrows its functions to the usage only within the framework of analytical constructions. The second way of development is 
supported by the fact that not all verbs may have non-finite participle II. Moreover, like bare infinitive, participle II formally coincides with some finite forms of the verb. The first direction is suggested taking into consideration the finite functioning of the participle. Within the framework of the analytic form of the perfect tenses participle loses its original semantic-syntactic essence - to determine the name, which is the object of its action, being subjected to complete desemantization and desintactization. In a perfect construction, a participle is associated with a name, which is a subject of the action, called by a participle. Thus it is also possible to speak about the expansion of the semantics of Participle II. Within the framework of the perfect construction, you can probably talk about the functional ambiguity of the participle. The syntactic nature of the verb "to have", characterized by the highest transitivity and therefore giving any object a similarity to the name implies the comparison of the participle II to the noun: He has a lot of experience He has experienced a lot.

\section{Conclusions}

It is not possible to resolve the question whether English has been piginized or not, since there are no specific criteria that could define a language as contact one. However, it should be noted that the necessary external conditions for pidginization actually existed in the history of the English language. The example of the changes that took place in the development of non-finite verbal paradigm proves the fact that a mechanism similar to the mechanism of the creolization process took place in the development of the English language. The structure of the Middle English non-finite verbal paradigm is significantly different from the Anglo-Saxon system.

\section{References}

1. Ch. J. Bailey, K. Maroldt, Langues en contact - Pidgins - Creoles, 21-53 (1977)

2. M. Görlach, Linguistics Across Historical and Geographical Boundaries, 329-344 (1986)

3. P. Poussa, Studia Anglica Posnaniensia 14, 69-85 (1982)

4. J. Milroy, Language in the British Isles 5-31 (1984)

5. Danchev, Studies in Middle English, 79-109 (1997)

6. A. R. Warner, Complementation in Middle English and the Methodology of Historical Syntax (1982)

7. O. Jespersen, Growth and structure of the English language (1912)

8. O. Jespersen, Progress in language with special reference to English (1894)

9. W. Rothwell, English Studies, 144-165 (1998)

10. T. Givôn, On understanding grammar (1979)

11. E.V. Perekhvalskaya, Sibirskij pidzhin (dalnevostochnyj variant) formirovanie. Istoriya. Struktura (2006)

12. M.V. Dyachkov, Voprosy yazykoznaniya 5, 122-132 (1988)

13. Ch. Dalton-Puffer, On the value of plausible speculation, Linguistic Change under Contact Conditions, 35-50 (1995)

14. R. J. Whitt, German linguistic and cultural studies 26 (2010)

15. A. Viberg, Linguistics 21, 123-162 (1984)

16. B. Gurajek, MSc by Research Linguistics (2010) 